\title{
Study of the relationship between Aedes (Stegomyia) aegypti egg and adult densities, dengue fever and climate in Mirassol, state of São Paulo, Brazil
}

\author{
Margareth Regina Dibo, Ana Patricia Chierotti', Mariana Silveira Ferrari', \\ Adriano Luis Mendonça', Francisco Chiaravalloti Neto/ ${ }^{1 /+}$ \\ Superintendência de Controle de Endemias ${ }^{1}$ Faculdade de Medicina de São José do Rio Preto, São José do Rio Preto, SP, Brazil
}

\begin{abstract}
The purpose of this study was to examine the relationship between Aedes aegypti egg and adult density indices, dengue fever and climate in Mirassol, state of São Paulo, Brazil, between November 2004-November 2005. Weekly collections of adults and eggs were made using, respectively, manual aspirators and oviposition traps that produced four entomological indices (positivity and average of females and eggs). Weekly incidence coefficients were calculated based on dengue cases. Each week, the data obtained from entomological indices were related to each other, dengue, and climate variables. The first index to show an association with dengue transmission was the female average, followed by female positivity and egg average. Egg positivity did not show a relationship with risk for dengue, but was sensitive to identifying the presence of the vector, principally in dry seasons. The relationship between climatic factors, the vector and the disease found in this study can be widely employed in planning and undertaking dengue surveillance and control activities, but it is a tool that has not been considered by the authorities responsible for controlling the disease. In fact, this relationship permits the use of information about climate for early detection of epidemics and for establishing more effective prevention strategies than currently exist.
\end{abstract}

Key words: Aedes aegypti - entomological indices - dengue - climate - Brazil

One of the key questions to be answered currently about Aedes aegypti concerns the best methods to use to undertake its entomological surveillance. These methods should be able to indicate priority areas to allow for stratification of control measures and help in the decision of which control strategies to use at a certain time. The primary purpose, however, should be to inform in terms of space and time about the risk of dengue occurrence (Focks 2003).

The most frequently used methods in Brazil are based on mosquito larval surveys as these are economically viable and easy to operate (MS 2002), in addition to their providing the Breteau, House and Container Indices (Focks 2003). However, these indices neither reflect potential dengue transmission nor identify areas with a greater risk for dengue (Focks 2003).

Among the available methods of entomological surveillance, adult mosquito collection is the technique that can best inform us about the quantity of adult mosquitoes and allow for the calculation of the number of $A e$. aegypti females per area or inhabitant, an index considered by Rodrigues-Figueroa et al. (1995) as the main predictor of dengue occurrence. Focks (2003) states that this is a method that can provide important information, principally in scientific investigations.

Financial support: FAPESP (2004/08594-8)

+ Corresponding author: fcneto@famerp.br

Received 10 April 2008

Accepted 17 September 2008
Another possibility is to use oviposition traps (Fay \& Eliason 1966) to indirectly estimate the female population. The traps have a low operating cost and are considered sensitive enough to detect the presence of the vector (Focks 2003, Morato et al. 2005). A good example of this method is the study carried out by Regis et al. (2008) that used the egg density index to identify areas with high concentrations of mosquitoes.

Other entomological measures are under consideration, such as the number of pupae per person or area (Focks 2003) and an index based on sticky traps that capture adult mosquitoes (Richie et al. 2003, Fávaro et al. 2008).

The relationship between climatic factors and $A e$. aegypti biology is well established for its interference in the efficiency of the vector in transmitting dengue (Watts et al. 1987, Focks et al. 1993, Kuno 1997, Scott et al. 2000, Tun-Lin et al. 2000, Hales et al. 2002). Many authors have established empirical relationships between climatic factors, the vector and dengue (Ram et al. 1998, Souza-Santos 1999, Hopp \& Foley 2001, Schreiber 2001, Hales et al. 2002, Hoeck et al. 2003, Vezzani et al. 2004, Nakhapakorn \& Tripathi 2005, Promprou et al. 2005, Favier et al. 2006, Rosa-Freitas et al. 2006, Chadee et al. 2007, Hurtado-Diaz et al. 2007, Surendran et al. 2007, Wongkoon et al. 2007, Wu et al. 2007), but the results have not been considered in the vector and dengue surveillance and control programs. It is therefore important to perform new studies and to use their results to prepare disease control strategies and plans (Ribeiro et al. 2006).

The objective of this study is to assess the concentration of Ae. aegypti females and their eggs by collecting adults and using oviposition traps. In addition, this study 
aims to examine the sensitivity of both methods and to relate the entomological indices to each other, dengue occurrence and climate.

\section{MATERIALS AND METHODS}

Study area - Mirassol is located in the Northwestern of São Paulo (Fig. 1) and in 2005 had a population of 53,991 (MS 2008). It was re-infested by Ae. aegypti in 1987 and transmission of dengue has been occurring since 1990.

Characteristics of the oviposition trap and aspiratorThe oviposition trap consists of an opaque black flask of approximately one liter. It is filled with $500 \mathrm{~mL}$ of water and a wooden pallet $12 \mathrm{~cm}$ long by $2 \mathrm{~cm}$ wide is placed inside. Drainage holes on each side of the container keep it from becoming completely full (Fay \& Eliasson 1966). The aspirator used was based on the model described by Nasci (Nasci 1981). It consists of a plastic pipe $62 \mathrm{~cm}$ long by $20 \mathrm{~cm}$ in diameter and contains a motor and propeller mounted on a $10 \mathrm{~W}$ fan. A tube of a mesh-like fabric was placed over it and fixed to the aspirator to capture the mosquitoes. The apparatus ran on a $12 \mathrm{~V}$ motorcycle battery.

Sample size in the study area - The city block was considered to be the sample unit in order to calculate the sample size. The positivity expected for the adult collections and oviposition traps was $50 \%$, with a precision of $10 \%$ and a confidence interval of $95 \%$. The sample size obtained by calculation was equal to 96 city blocks, which was rounded up to 100. In the first week of October 2004, 100 city blocks of a total of 781 comprising the urban area of the city of Mirassol (Fig. 1) were selected to undertake the proposed activities. The city blocks chosen had homogeneous characteristics in relation to the housing conditions and socioeconomic level of the inhabitants and containers were distributed evenly.

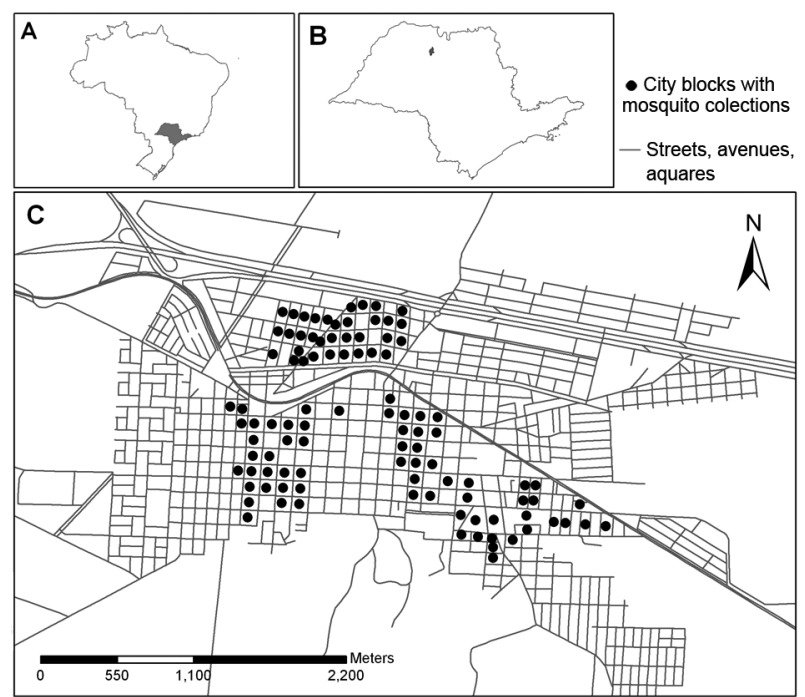

Fig. 1: A: map of Brazil and of the state of São Paulo (detail); B: map of the state of São Paulo and the municipality of Mirassol (detail); C: map of the urban area of Mirassol with location of 100 city blocks (black dots) where adult mosquitoes were aspirated and oviposition traps installed.
Data collection - In the period of November 16-19 2004, an oviposition trap was installed outside of a house in each of the selected city blocks (Fig. 1). Between the 4th week of November 2004 (epidemiological week 47) and the last week in November 2005 (epidemiological week 48), the egg traps were inspected every week. On each visit, the pallets were removed, individually packed in plastic bags and sent to the laboratory for egg counting, after which the flasks were washed, refilled with water and new pallets placed in position. The collected eggs were not kept for hatching and later identification because work done in the same county by Dibo et al. (2005) showed that the expected proportion of Ae. aegypti eggs in any one pallet was $99.2 \%$ with a confidence interval of $95 \%$ between $98.9 \%-99.5 \%$.

During the same period, adult mosquitoes were collected every week in a selected household per selected city block (Fig. 1). The households to be studied were chosen in a weekly drawing. Houses with traps were excluded from the drawing. The collections were made both inside and outside the houses. The captured adult mosquitoes were placed in cylindrical entomological boxes $(8 \times 8 \mathrm{~cm})$ and kept in polystyrene containing recyclable ice until they reached the laboratory, where they were identified.

Ae. aegypti females caught using aspirators were identified as being gravid or not by analyzing their ovarian development according to techniques described by Cristophers (1911) and Mer (1936). The presence or absence of blood in each female's midgut was checked and the status of any blood (digested or not) was noted (Barata et al. 2001).

Measured variables and data analysis - The positivity of Ae. aegypti females per household was calculated for each week by dividing the number of households with at least one Ae. aegypti female collected (times 100) by the number of households studied. The female average was calculated for each week by dividing the total number of Ae. aegypti females captured by the number of households studied. For the oviposition traps, the positivity of the traps and the egg average per trap were calculated for each week by dividing, respectively, the number of pallets with eggs present (times 100) and the total number of eggs collected by the number of traps studied.

The concordance between the data obtained from the oviposition traps and the adult collections was evaluated by calculating the Kappa concordance coefficient and the degree of discordance between the two methods was assessed using McNemar's non-parametric test (Landis $\&$ Koch 1977). A block was considered positive for adult collection when at least one Ae. aegypti adult female was found in the house surveyed and negative if none were found. Similarly, a block was considered positive for the oviposition trap when there was at least one egg in the trap surveyed and negative if there were none. The calculations were performed by pairing the information from both methods per block and week.

The autochthonous cases of dengue in Mirassol, confirmed by laboratory blood tests carried out by the Instituto Adolfo Lutz, were selected and the local health de- 
partment informed of the date of the start of symptoms during the study period. The weekly incidence coefficients were calculated per 100,000 inhabitants based on these cases. The four entomological indices (positivity and averages of females and eggs) and the incidence coefficients are shown in curves whose weekly values correspond to mobile averages with three values (the current week, the previous week and the subsequent week).

Rainfall information was obtained from the local agricultural department in Mirassol and temperature data were provided by the state agricultural bureau. The temperature data used were measured in São José do Rio Preto, since no data was available for Mirassol. São José do Rio Preto is $20 \mathrm{~km}$ away from the study area. Curves are shown with averages per week of the minimum, average, and maximum temperatures and the weekly accumulated rainfall.

The relationships between the four entomological indices, incidence coefficients and temperature and rainfall readings were assessed by comparing the formats of their weekly curves.

Committee of Research Ethics - This study was presented to and approved by the Ethical Committee of Faculdade de Medicina de São José do Rio Preto (protocol n. 286/2004).

\section{RESULTS}

For the 54 weeks of the study, 19,974 examples of culicids were caught using Nasci aspirators, 17,791 (89.07\%) Culex sp., 2,174 (10.88\%) Ae. aegypti (1088 male and 1086 female), six (0.03\%) Anopheles sp. and three $(0.02 \%)$ Aedes albopictus (1 male and 2 females). The oviposition traps caught 165,607 eggs. During this period, 173 autochthonous cases of dengue were recorded and confirmed in the laboratory.

Among the Ae. aegypti adults caught by the aspirators, $78.4 \%$ (95\% CI: $75.8-80.8$ ) of females and $60.9 \%$ (95\% CI: 57.9-63.8) of males were found inside the homes. Of the females caught, $58.6 \%$ (95\% CI: 55.6-61.5) were gravid, 38.4\% (95\% CI: 35.5-41.1) were not, and it was not possible to analyze $3.1 \%$ (95\% CI: 2.1-4.3). Bloodless females represented $24.2 \%$ (95\% CI: $21.7-26.9$ ), whereas $38.1 \%$ (95\% CI: $35.2-41.1)$ of females contained recently ingested blood, 35.5\% (95\% CI: 32.7-38.3) digested blood, and $2.1 \%$ (95\% CI: 1.4-3.2) could not be examined.

Figs 2 and 3 show the positivity and average number of Ae. aegypti females per household and the positivity and average number of eggs per trap, respectively, in conjunction with the curve of the dengue incidence coefficients during the 54 weeks of the study. Fig. 4 shows the curves for the average, maximum and minimum temperature and rainfall.

The shapes of the curves for positivity and average number of females were similar throughout the period under study. The curves of female and egg averages were similar for part of the period but differed between weeks 23-39/05. While the female averages oscillated up and down in value, the egg averages had low values. The egg average and positivity curves had a similar pattern between epidemiological weeks 47/04-1/05 and between

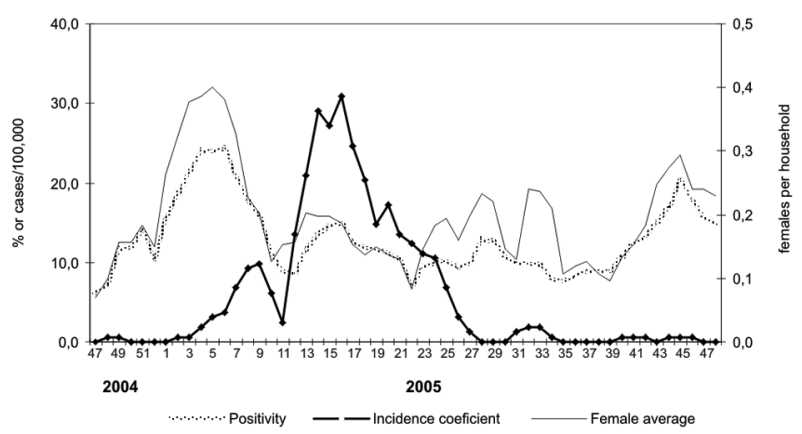

Fig. 2: positivity and average of Aedes aegypti females per household captured using Nasci (Nasci 1981) aspirators and coefficients of incidence of dengue in epidemiological weeks, Mirassol, São Paulo, November 2004 -December 2005.

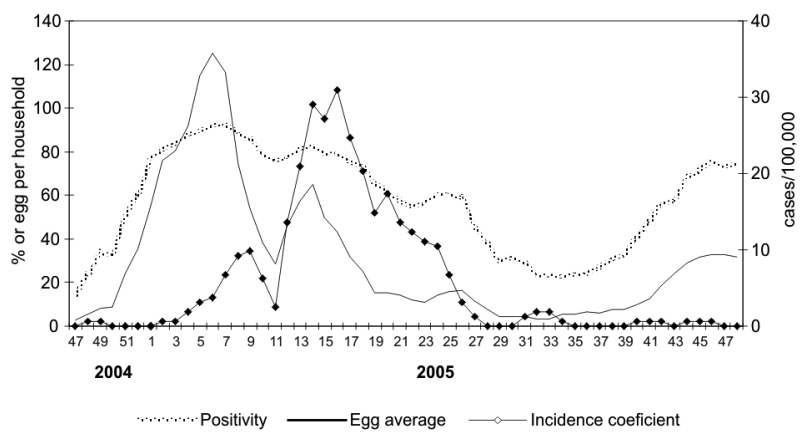

Fig. 3: positivity and egg average in oviposition traps and coefficients of dengue incidence in epidemiological weeks, Mirassol, São Paulo, November 2004-December 2005.

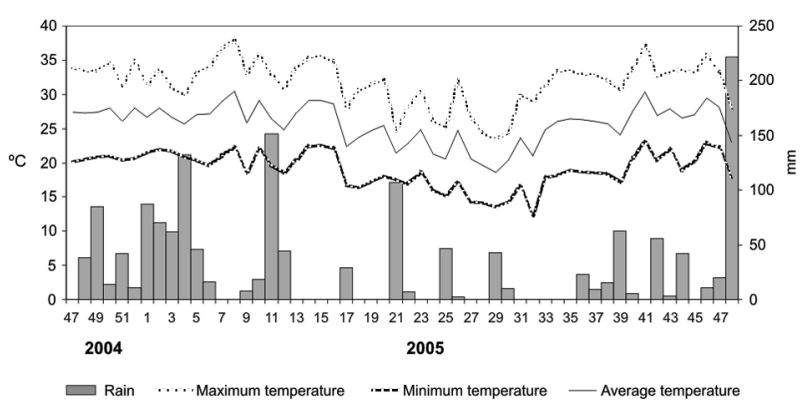

Fig. 4: temperatures $\left({ }^{\circ} \mathrm{C}\right)$ and rainfall $(\mathrm{mm})$ in epidemiological weeks, Mirassol, São Paulo, November 2004-December 2005.

weeks 15-48/05. Between weeks 2-14/05, positivity reached a high level $(76.1 \%$ to $92.9 \%)$ and the averages peaked in week 6 , followed by a drop at week 11 and a new rise in week 14/05.

The Kappa concordance coefficient calculated between the results of the oviposition traps and manual aspirations was 0.0495 (a very slight concordance) $(\mathrm{p}<0.0001)$. McNemar's test, relating the same information, had a very significant result $(\mathrm{p}<0.0001)$, showing discordance between the two methods. Considering the entire study period, the positivity of the traps was $58.0 \%$ (95\% CI: 56.7-59.3) and positivity of the aspirations was $13.0 \%$ (95\% CI: 12.1-13.9) (Table). 
TABLE

Concordance between positivity of collection using Nasci aspirators for Aedes aegypti females and oviposition trap, Mirassol, São Paulo, November 2004-December 2005 ${ }^{a}$

\begin{tabular}{lcrrrrrr}
\hline & \multicolumn{8}{c}{ Oviposition trap } \\
\cline { 2 - 8 } Type of collection & \multicolumn{1}{c}{ Positive } & \multicolumn{2}{c}{ Negative } & \multicolumn{1}{c}{ Total } \\
\cline { 2 - 8 } & & $\mathrm{n}$ & \multicolumn{1}{c}{$\%$} & $\mathrm{n}$ & $\%$ & $\mathrm{n}$ & $\%$ \\
\hline Aspiration & Positive & 474 & 8.9 & 216 & 4.1 & 690 & 13.0 \\
& Negative & 2617 & 49.1 & 2021 & 37.9 & 4638 & 87.0 \\
\hline & Total & 3091 & 58.0 & 2237 & 42.0 & 5328 & 100.0 \\
\hline
\end{tabular}

$a$ : Kappa concordance coefficient: 0.0495 ( $\mathrm{p}<0.0001$, very slight concordance).

The increase in cases of dengue between weeks 2-9/05 corresponded to the rise in values of the four entomological indices, with the highest peaks occurring between weeks 5-7/05. The increases shown by the indices were related to heavy rainfall intensity and frequency between weeks 48/04-06/05. The drop in incidences between weeks 9-11/05 and another rise also corresponded to the entomological indices, except for the egg positivity. While the highest peak of incidence occurred in week $16 / 05$, secondary peaks of the female average, egg average and female positivity occurred in weeks 13,14 and $16 / 05$, respectively. In turn, the drop followed by another rise in the three entomological indices was related to the rainfall pattern, which had dropped in intensity and frequency between weeks 7-9/05 and increased between weeks 10-12/05. Temperatures remained high throughout this period.

The drop in incidences from week $16 / 05$ and the occurrence of zero or very low values from week 27/05 corresponded with the drop found in egg averages and positivities and displayed a partial relationship with female average and positivity, which showed a drop until week 22 and oscillations until week 35/05. In this period, rainfall was less frequent and intense and temperatures dropped, with the minimum temperature reaching its lowest value in week $32 / 05\left(12.3^{\circ} \mathrm{C}\right)$.

The temperature increase beginning in week 32 and frequency and intensity of rainfall increase beginning in week 36/05 were related to the increase in values of the four entomological indices observed beginning in week $39 / 05$.

\section{DISCUSSION}

Rodrigues-Figueroa et al. (1995) and Focks (2003) found that the density of adult females is the best entomological indicator to explain the occurrence of dengue, which was confirmed in this study. With a gap of three to four weeks, the curve of dengue incidence followed the curve of female averages per household until week $22 / 05$. Although the curves of female positivities and egg averages had shown similar behavior to that of the incidence curve, there was a lag of one to two weeks between the first two and the female average curve so that the latter would be faster in detecting the increase in density of the vector. From the viewpoint of predicting dengue transmission, this can be an advantage for this entomological indicator.
The high egg positivities in the period when the vast majority of dengue cases occurred made it unfeasible to use this indicator as a risk measurement, since it failed to identify in time the density peaks and most propitious moments for transmitting the disease, ideal for adopting epidemiological surveillance and vector control measures. Regis et al. (2008) also found very high egg positivities in a study with modified ovitraps carried out in Recife, Brazil. On the other hand, egg positivity is considered the most sensitive indicator for identifying the presence of Ae aegypti (Focks 2003, Morato et al. 2005), even when compared to adult collection (Schultz 1993, Romero-Vivas \& Falconar 2005). This result is confirmed in the present study. Although not suitable as a risk measure for dengue, its strong sensitivity enables this measure to be used as a good tool for monitoring at the most unfavorable times for the mosquito (dry seasons and/or with lower temperatures) (Schultz 1993). It therefore permits identification of places where the vector is present and where control actions should be taken to prevent their transforming into breeding grounds for more mosquitoes during the rainy seasons.

The female average and positivity and egg average had a close relationship with the rain and temperature patterns. To a lesser extent, this also happened with egg positivity. During the period of higher temperatures, the female average and positivity and egg average followed the rainfall patterns with a time lag. A drop in temperature and less rainfall determined the drop in all indicators, which increased again with another rise in temperature and rainfall.

These results are consistent with the literature. Vezzani et al. (2004) found greater proliferation of Ae. aegypti eggs and larvae during periods of higher temperatures and greater rainfall. Surendran et al. (2007) and Hoeck et al. (2003) showed that there was an association between egg density and rainfall intensity and SalasLuévano and Reyes-Villanueva (1994) found that captured females peaked during times of heavier rainfall. Hopp and Foley (2001) demonstrated, in models, that climate variables can explain a large part of the seasonal variation of Ae. aegypti. Favier et al. (2006), studying the relationship between climate and Ae. aegypti in an area of Brasília, Brazil, found an association between the Container Index and relative humidity, the number of water-holding containers and rainfall and the mean number of pupae per positive container and mean tem- 
perature. Souza-Santos (1999) identified, in a neighborhood in Rio de Janeiro, Brazil, meteorological variables as the principal determinant factors of the occurrence of Ae. aegypti larvae and pupae.

Several studies have shown the influence of climatic factors over the biology of Ae. aegypti. Higher temperatures can increase the mosquito's survival rate and accelerate its reaching the adult phase (Tun-Lin et al. 2000), rainfall increases the number of mosquito breeding places and their abundance (Kuno 1997), and high relative humidity where there are high temperatures and heavy rainfall also has a positive influence on the survival and breeding conditions of the mosquito (Hales et al. 2002). Climatic factors also interfere in the efficiency of the vector in transmitting dengue. Higher temperatures reduce the extrinsic incubation period and increase the replication rate of the virus (Watts et al. 1987) and the number of blood meals during a gonotrophic cycle (Scott et al. 2000). High moisture also contributes to increased virus replication (Focks et al. 1993). These characteristics give support, from the biological viewpoint, to the correspondence of the curve of dengue incidence with the curves of female average, positivity and egg average and the correspondence of these curves with temperature and rainfall curves.

Many authors have studied the climate-dengue ratio, since it can be used to predict transmission. Foo et al. (1985), Schultz (1993) and Chadee et al. (2007) have found an association with rainfall; Wongkoon et al. (2007), with temperature; Ribeiro et al. (2006), with rainfall and temperature; Ram et al. (1998), with temperature and moisture; and Nakhapakorn and Tripathi (2005) and Promprou et al. (2005), with temperature, rainfall, and moisture. Hales et al. (2002) found that moisture was the most important predictor of dengue occurrence. Hurtado-Diaz et al. (2007) showed that a rise in the minimum temperature, rainfall and surface temperature of the sea (as an indicator of the El Niño phenomenon) was associated with an increase in dengue transmission levels in the coastal towns on the Gulf of Mexico, prepared a prediction model using time series, and proposed the development of an early warning system based on climate data for prevention and control of dengue epidemics.

The time lag found in this study between climatic factors and dengue has been considered by some authors in their studies (Foo et al. 1985, Schultz 1993, Schreiber 2001, Nakhapakorn \& Tripathi 2005, Hurtado-Diaz et al. 2007, Wu et al. 2007), increasing the explanatory power of the ratio findings. Foo et al. (1985) believe that rainfall, as an early indicator, has faster prediction capacity than the slower entomological indicators. Schreiber (2001) showed, in San Juan, Puerto Rico, that dengue incidence was significantly influenced by climate over at least an 8-week period, using a water budgeting technique. Wu et al. (2007), using autoregressive integrated moving average models, found an association of dengue incidence in Taiwan with temperature and relative humidity. These presented their strongest effects at a time lag of two months, but not in the case of rainfall. This occurred because the majority of the breeding sites were filled with water by people. This is not the case in Mirassol, where the majority of the breeding places were filled with rain water (Secretaria de Saúde de Mirassol).

In this study, the fastest index related to dengue transmission was the female average, followed by female positivity and egg average. The routine use of the female average has the disadvantage that catching females using aspirators incurs a high operating cost (Focks 2003), but alternative methods of capturing adults, such as sticky ovitraps, can be used (Richie et al. 2003, Fávaro et al. 2008). The egg positivity did not prove to be a good risk measure for dengue, but it is sensitive to identifying the presence of the vector, principally during the dry seasons. However, the egg average, which showed a good relationship to female average, climate variables and dengue incidence, could also be a good measure of risk, principally because it has a low operating cost and it is easy to carry out. Regis et al. (2008) used the egg average to identify areas with high concentrations of mosquitoes. They considered this strategy a good one to detect and prevent Ae. aegypti population outbreaks and, consequently, a good measure of dengue risk.

It is important to stress the possible existence of bias in this study: the use of information about reported dengue fever cases may represent only part of the total number of dengue virus infections, the rainfall data was obtained for a location not exactly at the mosquito collection site, and the temperatures were available only for a neighboring city. We did not take into account moisture data because they were not available for Mirassol. However, the results and conclusions of this study are valid because it is easy to conclude that the reported dengue cases are well related to the total number of infections, the available municipal rainfall information is a good estimate of the rainfall in the study area, the temperatures of São José do Rio Preto and Mirassol do not vary much because these cities are close to each other and have similar climatic conditions according to the state agricultural bureau of São Paulo, and the moisture data are correlated with temperatures and rainfall and are well represented by them. In addition, this information is the type of available data used by the services that are responsible for dengue surveillance and control and could be used to improve disease control.

The relationships found here will be modeled using a suitable statistical technique. To do this, moisture data that could be a good surrogate for the moisture data at the study site, climatic variables not normally used in this type of study [such as those related to the water budget (Schreiber 2001), atmospheric pressure and wind (Rosa-Freitas et al. 2006)], and information about vector control measures developed during the study period will be all considered if the necessary data are available.

The climatic variations alone do not explain the $A e$. aegypti and dengue distributions. Factors such as the abundance of the breeding sites and how they are filled with water, the domestic behavior of the vector that protects it against fluctuations in temperature and humidity, the degree of immunity of the population against the dengue virus serotypes, and many other factors should be considered in the design of explanatory epidemiologi- 
cal models of dengue occurrence. Apart from these issues, climate is a very important component of the spatial and temporal distribution of dengue (Rosa-Freitas et al. 2006, Wu et al. 2007). Therefore, the relationship between climatic factors, the vector and the disease identified in this and various other studies has widespread application in planning and undertaking surveillance and dengue control activities, although it is a tool that has not been considered by the authorities responsible for controlling the disease. It permits the use of information about climate for early detection of epidemics and for establishing more effective prevention strategies than those currently developed (Schreiber 2001, Focks 2003, Favier et al. 2006, Ribeiro et al. 2006, Rosa-Freitas et al. 2006, Wu et al. 2007).

\section{ACKNOWLEDGMENTS}

To Adriano Mondini, Aline C Ferreira, Angelita AC Barbosa, Eliane A Fávaro and Marlene CG Souza, for assistance with the field work, and to Beatriz AC Belini, Neuza FA Santana and Perpétua MM Sereno, for assistance with the laboratory work.

\section{REFERENCES}

Barata EAMF, Costa AIP, Chiaravalloti-Neto F, Glasser CM, Barata JMS, Natal D 2001. Populations of Aedes aegypti (L.) in a dengueendemic area, Southeast Brazil. Rev Saude Publica 35: 237-242.

Chadee DD, Shivnauth B, Raulins SC, Chen AA 2007. Climate, mosquito indices and the epidemiology of dengue fever in Trinidad (2002-2004). Ann Trop Med Parasitol 101: 69-77.

Christophers SR 1911. The development of the egg follicle in Anophelines. Paludism 2: 73-78.

Dibo MR, Chiaravalloti-Neto F, Battigaglia M, Mondini A, Fávaro A, Barbosa AAC, Glasser CM 2005. Identification of the best ovitrap installation sites for gravid Aedes (Stegomyia) aegypti in households in Mirassol, state of São Paulo, Brazil. Mem Inst Oswaldo Cruz 100: 339-343.

Fávaro EA, Mondini A, Dibo MR, Barbosa AAC, Eiras AE, Chiaravalloti-Neto F 2008. Assessment of entomological indicators of Aedes aegypti (L.) from adult and egg collections in São Paulo, Brazil. J Vector Ecol 33, in press.

Favier C, Degallier N, Vilarinhos PTR, Carvalho MSL, Yoshizawa MAC, Knox MB 2006. Effects of climate and difference management strategies on Aedes aegypti breeding sites: a longitudinal survey in Brasília (DF, Brazil). Trop Med Inter Health 11: 1104-1118.

Fay RW, Eliason DA 1966. A preferred oviposition site as a surveillance method for Aedes aegypti. Mosq News 26: 531-535.

Focks DA 2003. A Review of Entomological Sampling Methods and Indicator for Dengue Vectors, World Health Organization, Gainesville, 40 pp.

Focks DA, Haile DG, Daniels E, Mount GA 1993. Dynamic life table model for Aedes aegypti (Diptera: Culicidae): analysis of the literature and model development. J Med Entomol 30: 1003-1017.

Foo LC, Lim TW, Lee HL, Fang R 1985. Rainfall, abundance of Aedes aegypti and dengue infection in Selangor, Malaysia. Southeast Asian J Trop Med Pub Health 16: 560-568.

Hales S, Wet N, Maindonald J, Woodward A 2002. Potential effect of population and climate changes on global distribution of dengue fever: an empirical model. Lancet 360: 830-834.

Hoeck PAE, Ramberg FB, Merrill SA, Moll C, Hagedorn HH 2003.
Population and positivity levels of Aedes aegypti collected in Tucson. J Vector Ecol 28: 1-9.

Hopp MJ, Foley JA 2001. Global-scale relationships between climate and the dengue fever vector, Aedes aegytpi. Clim Change 48: 441463.

Hurtado-Diaz M, Riojas-Rodríguez H, Rothemberg SJ, Gómez-Dantés H, Cifuentes E 2007. Impact of climate variability on the incidence of dengue in Mexico. Trop Med Int Health 12: 1327-1337.

Kuno G 1997. Factors influencing the transmission of dengue viruses. In DJ Gubler, G Kuno, Dengue and Dengue Haemorrhagic Fever, CAB International, London, p. 61-87.

Landis JR, Koch GG 1977. The measurement of observer agreement for categorical data. Biometrics 33: 159-174.

Mer GG 1936. Experimental study on the development of the ovary in Anopheles elutus Edw. (Diptera: Culicidae). Bull Entomol Res 27: 351-359.

Morato VCG, Teixeira MG, Gomes AC, Bergamaschi DP, Barreto ML 2005. Infestation of Aedes aegypti estimated by oviposition traps in Brazil. Rev Saude Publica 39: 553-558.

MS - Ministério da Saúde 2002. Fundação Nacional de Saúde, Programa Nacional de Controle da Dengue, Brasília, Brazil, 32 pp.

MS - Ministério da Saúde 2008. Departamento de Informática do Sistema Único de Saúde. Brasilia, Brazil. Available at http://tabnet. datasus.gov.br/cgi/tabcgi.exe?ibge/cnv/popsp.def [update 2006 Jan 02; cited 2008 Ago 4].

Nakhapakorn K, Tripathi NK 2005. An information value-based analysis of physical and climatic factors affecting dengue fever and dengue haemorrhagic fever incidence. Int J Health Geogr 4: 1-13.

Nasci RS 1981. A light weight battery-powered aspirator for collecting mosquitoes in the field. Mosq News 41: 808-811.

Promprou S, Jaroensutasinee M, Jaroensutasinee K 2005. Climatic factors affecting dengue haemorrhagic fever incidence in Southern Thailand. Dengue Bulletin 29: 41-48.

Ram S, Khurama S, Kaushal V, Gupta R, Khurama SB 1998. Incidence of dengue fever in relation to climatic factors in Ludhiana, Punjab. Indian J Med Res 108: 128-133.

Regis L, Monteiro AM, Melo-Santos MAV, Silveira JC, Furtado AF, Acioli RV, Santos GM, Nakazawa M, Carvalho MS, Ribeiro Jr PJ, Souza WV 2008. Developing new approaches for detecting and preventing Aedes aegypti population outbreaks: basis for surveillance, alert and control system. Mem Inst Oswaldo Cruz 103: 50-59.

Ribeiro AF, Marques GRAM, Voltolini JC, Condino MLF 2006. Associação entre incidência de dengue e variáveis climáticas. Rev Saude Publica 40: 671-676.

Ritchie SA, Long S, Hart A, Webb CE, Russel RC 2003. An adulticidal sticky ovitrap for sampling container-breeding mosquitoes. J Am Mosq Contr Assoc 19: 235-242.

Rodriguez-Figueroa L, Rigau-Perez JG, Suarez EL, Reiter P 1995. Risk factors for dengue infection during an outbreak in Yanes, Puerto Rico in 1991. Am J Trop Med Hyg 52: 496-502.

Romero-Vivas C, Falconar AKI 2005. Investigation of relationships between Aedes aegypti egg, larvae, pupae, and adult density indices where their main breeding sites were located indoors. $J \mathrm{Am}$ Mosq Contr Assoc 21: 15-21.

Rosa-Freitas MG, Schreiber KV, Tsouris P, Weimann ETS, LuitgradsMoura JF 2006. Association between dengue and combinations of weather factors in a city in the Brazilian Amazon. Pan Am J Public Health 20: 256-267. 
Salas-Luévano MA, Reyes-Villanueva F 1994. Variación estacional de las poblaciones de Aedes aegypti em Monterrey, Mexico. Salud Pública Méx 36: 385-392.

Schreiber KV 2001. An investigation of relationships between climate and dengue using a water budgeting technique. Int $J$ Biometeorol 45: 81-89.

Schultz GW 1993. Seasonal abundance of dengue vectors in Manila, Republic of the Philippines. Southeast Asian J Trop Med Pub Health 24: 369-375.

Scott TW, Amerasinghe PH, Morrison AC, Lorenz LH, Clark GC, Strickman D, Kittayapong P, Edman JD 2000. Longitudinal studies of Aedes aegypti (Diptera: Culicidae) in Thailand and Puerto Rico: blood feeding frequency. J Med Entomol 37: 89-101.

Souza-Santos R 1999. Fatores associados à ocorrência de formas imaturas de Aedes aegypti na Ilha do Governador, Rio de Janeiro, Brasil. Rev Soc Bras Med Trop 32: 373-382.

Surendran NS, Kajatheepan A, Sajeefkumar KFA, Jude PJ 2007. Seasonality and insecticide susceptibility of dengue vectors: an ovitrap based survey in a residential area of Northern Sri Lanka. Southeast Asian J Trop Med Pub Health 38: 276-282.

Tun-Lin, Burkot TR, Key BH 2000. Effects of temperature and larval diet on development rates and survival of the dengue vector Aedes aegypti in north Queensland, Australia. Med Vet Entomol 14: 31-37.

Vezzani D, Velazquez SM, Schweigmann N 2004. Seasonal pattern of abundance of Aedes aegypti (Diptera: Culicidae) in Buenos Aires city, Argentina. Mem Inst Oswaldo Cruz 99: 351-356.

Watts DM, Burke DS, Harrison BA, Whitmire RE, Nisalak A 1987. Effect of temperature on the vector efficiency of Aedes aegypti for dengue 2 virus. Am J Trop Med Hyg 36: 143-152.

Woogkoon S, Jaroensutasinee M, Jaroensutasinee K, Preechaporn W, Chumkiev S 2007. Larval occurrence and climatic factors affecting DHF incidence in Samui Islands, Thailand. Int J Biomed Sci 2: $107-112$.

Wu PC, Guo HR, Lung SC, L CY, Su HJ 2007. Weather as an effective predictor for occurrence of dengue fever in Taiwan. Acta Tropical 103: 50-57. 